\title{
Modeling the fluid/soil interface erosion in the Hole Erosion Test
}

\author{
B.Kissi ${ }^{1,2}$, M.Angel Parron Vera ${ }^{2}$, M.D.Rubio Cintas $^{2}$, and A.Khamlichi ${ }^{1}$ \\ ${ }^{1}$ Department of Physics, Faculty of Sciences at Tetouan, Morocco \\ ${ }^{2}$ Industrial and Civil Engineering Department, Polytechnic High School of Algeciras, University of Cadiz, Spain
}

\begin{abstract}
Soil erosion is a complex phenomenon which yields at its final stage to insidious fluid leakages under the hydraulic infrastructures known as piping and which are the main cause of their rupture. The Hole Erosion Test is commonly used to quantify the rate of piping erosion. In this work, The Hole Erosion Test is modelled by using Fluent software package. The aim is to predict the erosion rate of soil during the hole erosion test. The renormalization group theory - based $k-\varepsilon$ turbulence model equations are used. This modelling makes it possible describing the effect of the clay concentration in flowing water on erosion. Unlike the usual one dimensional models, the proposed modelling shows that erosion is not uniform erosion along the hole length. In particular, the concentration of clay is found to increase noticeably the erosion rate.
\end{abstract}

\section{Introduction}

Many dam ruptures events have occurred throughout the world, some of them were reported by Foster et al. [1]. Then main cause of these ruptures was identified to be related to piping phenomenon that occurred in the foundation soil or in the dams structure. Serviceability of hydraulic infrastructures needs considering vulnerability of soil under the action of seepage flow, [2-4]. For unconsolidated soils that are formed with cohesion less assembly of sand particles, the flowing water velocity plays an important role on erosion phenomenon that could happen. Understanding the underlying mechanisms and quantifying the effects of pertinent variables on this phenomenon is of great importance in practice. Sand erosion due to liquid flow discharge can be modelled by different approaches. These include continuum based models and discrete models. The common feature for all the continuum-based models is that they require establishment of the conditions under which sand failure will occur. They use for that some parameters which are calibrated with laboratory tests or field observations in order to predict when erosion starts and the expected erosion rate. Various models for prediction of sand erosion rate have been developed in the literature: [4-5]. Among the important tests that are used to predict erosion, one finds the Hole Erosion Test (HET). A model for interpreting the HET with a constant pressure drop was developed by Bonelli and Brivois [6]. This model yielded a characteristic erosion time which was found to be depending on the initial hydraulic gradient and the soil coefficient of erosion.

Additional aspects associated to some twodimensional features of the HET are present in the problem. For instance, the inlet side of the hole undergoes generally much more erosion than the outlet side. But, one-dimensional modelling of this test could not predict this eroded shape since it yields uniform erosion at the whole fluid/soil interface inside the soil sample.

The aim of this study is to describe the biphasic turbulent flow at the origin of erosion taking place inside the porous soil sample, considering the influence of variation of the concentration of clay in the flowing fluid. A Computational Fluid Dynamics (CFD) approach will be used to investigate the shear stress that develops at the water/soil interface and which represents the main mechanical action that cause surface erosion.

\section{CFD modelling approach of erosion in the HET}

The turbulence modelling of water flowing inside the hole of the HET sample is achieved by means of Fluent software package. Fluent is a general purpose CFD code that has been applied to various problems in the fields of fluid mechanics and heat transfer. This code has been validated through numerous investigations. Fluent is especially appropriate for the complex physics involved in heat and mass transfer and considers mixtures by 
modeling each fluid phase independently or as a homogenized medium, [7].

Flow taking place inside the hole is turbulent. To perform realistic simulation of turbulence, the exact instantaneous Navier-Stokes governing equations are habitually timeaveraged or ensemble-averaged. The obtained averaged equations contain further unknown variables, and turbulence models are introduced in order to determine them in terms of known quantities. Various turbulence models have been proposed in the literature; however there is no single turbulence model which could be applied for all classes of problems. The choice of a pertinent model for a given problem will depend on the actual physics of the flow, the degree of accuracy required and the computational cost tolerated. Fieldview Reference Manual [8] gives a detailed discussion on how to perform at best the appropriate choice of a turbulence model. Among the various models, the standard $k-\varepsilon$ model which was proposed first by Launder and Spalding [9] has become the most popular one when dealing with practical engineering flow calculations. This model relies on phenomenological considerations and integrates empiricism to perform closure of turbulence equations.

Improvements of the standard $k-\varepsilon$ model such as the RNG $k-\varepsilon$ model have been made, [10]. This model was derived by using a rigorous statistical technique called Renormalization Group Theory (RNG). In comparison with the standard $k-\varepsilon$ model, RNG model includes refinements which significantly improve the accuracy for rapidly strained flow. In contrast with the standard $k-\varepsilon$ model which is rather designed for high Reynolds numbers and for which the effective viscosity is constant, the RNG theory provides an analytically derived differential formula for effective viscosity that accounts also for low Reynolds number effects. Use of this feature requires however an appropriate treatment of the near-wall region. These advantages make the RNG base $-k-\varepsilon$ model more accurate and reliable for a wider class of flows than the standard $k-\varepsilon$ model.

For further details, a complete description of RNG theory and its application to turbulence modelling can be found in [10-12]. Among the family of $k-\varepsilon$ turbulence based models Fluent [13] provides the following choices: the standard $k-\varepsilon$ model, the RNG based $-k-\varepsilon$ model and the Realizable $k-\varepsilon$ model. Because of its relevance which was stated through various investigations, use is made subsequently of the RNG $k-\varepsilon$ model. The governing equations of this model are recalled in the following. Special treatment of near wall boundary conditions as proposed by Fluent was used.

\section{RNG based $k-\varepsilon$ erosion model equations for the HET}

The RNG $k-\varepsilon$ model differs from the standard model by the special form of the transport equations which contain the additional term $R_{\varepsilon}$. These equations write

$$
\begin{aligned}
& \frac{\partial k}{\partial t}+\frac{1}{r} \frac{\partial(r k u)}{\partial r}+\frac{\partial(k v)}{\partial z}=\frac{1}{r} \frac{\partial}{\partial r}\left(\alpha \mu_{t} r \frac{\partial k}{\partial r}\right)+\frac{\partial}{\partial z}\left(\alpha \mu_{t} \frac{\partial k}{\partial z}\right) \\
& +\alpha \mu_{t} \frac{k}{r^{2}}+\mu_{t} S^{2}-\varepsilon \\
& \frac{\partial \varepsilon}{\partial t}+\frac{1}{r} \frac{\partial(r \varepsilon u)}{\partial r}+\frac{\partial(\varepsilon v)}{\partial z}=\frac{1}{r} \frac{\partial}{\partial r}\left(\alpha \mu_{t} r \frac{\partial \varepsilon}{\partial r}\right)+\frac{\partial}{\partial z}\left(\alpha \mu_{t} \frac{\partial \varepsilon}{\partial z}\right) \\
& +\alpha \mu_{t} \frac{k}{r^{2}}+C_{1 \varepsilon} \frac{\varepsilon}{\rho k}-C_{2 \varepsilon} \frac{\varepsilon^{2}}{\rho k}-\frac{1}{\rho} R_{\varepsilon}
\end{aligned}
$$

With

$$
\begin{aligned}
& R_{\varepsilon}=\frac{C_{\mu} \rho S^{3} k^{2} \varepsilon\left(\eta_{0} \varepsilon-S k\right)}{\eta_{0}\left(\varepsilon^{3}+\beta S^{2} k^{3}\right)} \\
& S^{2}=2\left(\frac{\partial u}{\partial r}\right)^{2}+2\left(\frac{\partial v}{\partial z}\right)^{2}+\left(\frac{\partial v}{\partial r}+\frac{\partial u}{\partial z}\right)^{2}
\end{aligned}
$$

where $r$ and $z$ are the axial and radial coordinates, $t$ is time, $u$ and $v$ are the mean radial and axial flow velocities, $k$ is the turbulent kinetic energy, $\varepsilon$ the rate of dissipation of turbulent kinetic energy, $\rho$ is the fluid density, $\mu_{t}$ the total kinematics viscosity, $\alpha$ is the inverse effective Prandtl number for both $k$ and $\varepsilon, C_{1 \varepsilon}$, $C_{2 \varepsilon}, C_{\mu}, \eta_{0}$ and $\beta$ are constants

The RNG $k-\varepsilon$ model constants have values derived analytically by the RNG theory. They are given by $C_{1 \varepsilon}=1.42, \quad C_{2 \varepsilon}=1.68, C_{\mu}=0.0845, \quad \eta_{0}=4.38$ and $\beta=0.012$.

To compute distribution of shear stress on the inner wall of the hole, boundary conditions should be entered. When the shear stress is calculated by means of Fluent, the classical linear erosion law is used to estimate erosion rate. This law states that erosion rate considered to be the amount of mass departure due to erosion per unit time and by unit surface area, is given by: $\dot{\varepsilon}_{e r}=c_{e r}\left(\tau-\tau_{c r}\right)$ where $c_{e r}$ and $\tau_{c r}$ are constant depending on the considering soil material. The rate $\dot{\varepsilon}_{e r}$ can be related to time variation of local radius by $\dot{\varepsilon}_{e r}=\rho_{d} d R / d t$ where $\rho_{d}$ is the dry density of soil and $R$ is the inner radius of the hole. The erosion law yields that $\dot{\varepsilon}_{e r}$ is proportional to the amount of shear exceeding the critical shear $\tau_{c r}$ for which erosion begins.

\section{Results and discussions}

The fluid domain which is assumed to be axisymmetric extends over $117 \mathrm{~mm}$ in the axial z-direction and $3 \mathrm{~mm}$ in the radial r-direction. The domain is oriented such that the inlet section is at left and the outlet section is at right, figure 1 and 2 . 


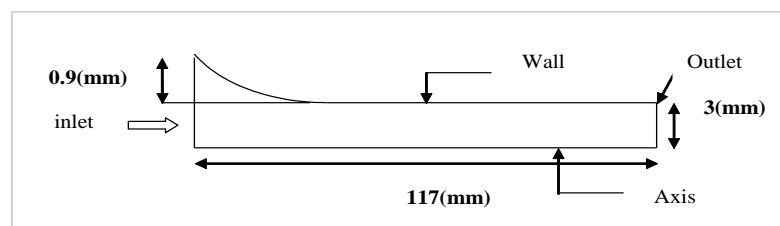

Fig.1. Geometry of the HET tube

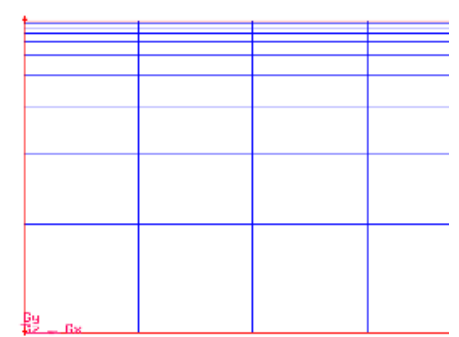

Fig. 2. A view detailing the mesh used for the HET tube

The origin of the reference frame is placed at the entrance section. Figure 2 gives a detailed view of the mesh used under Fluent.

During simulations, the boundary conditions that were used are the following:

- Inlet at the left extremity of the domain.

- Outlet at the right extremity of the domain.

- Symmetry type axis at the axis of symmetry

which is the bottom side of the domain as presented in figure 1 .

- Wall at the top side of the domain. This boundary conditions uses the enhanced boundary wall as provided by Fluent.

Table 1: Homogenized density and viscosity for waterclay mixtures as function of clay concentration

\begin{tabular}{|c|c|c|}
\hline $\begin{array}{l}\text { Concentration of clay } \\
\text { in \% }\end{array}$ & $\begin{array}{l}\text { Density of the } \\
\text { mixture } \mathrm{kg} / \mathrm{m}^{3} \text { ) }\end{array}$ & $\begin{array}{l}\text { Viscosity of the } \\
\text { mixture ( Pa.s })\end{array}$ \\
\hline 0 & 1000 & 0.001 \\
\hline 3.85 & 1020 & 0.00194 \\
\hline
\end{tabular}

Table 1 gives the mixture parameters used for the liquid flowing inside the hole of the HET. The take into account the effect of clay concentration on both density and viscosity at temperature $20^{\circ} \mathrm{C}$.

Figure 3 shows for the two clay concentrations the axial velocity when the applied pressure is $\mathrm{P}=3127(\mathrm{~Pa})$.

Figure 4 shows shear stress that develops at the soil sample interface with flowing flow for pressure $\mathrm{P}=3726$ (Pa).

Figure 5 shows for the two clay concentration the calculated erosion rate which is given in $10^{-6} \mathrm{~kg} / \mathrm{s}$. This amount is obtained by integrating the erosion law over the whole length of the hole and by multiplying the result by the initial circumference of the hole. The erosion constants that were used are: $c_{e r}=5.5 \times 10^{-4} \mathrm{~s} / \mathrm{m}$ and $\tau_{c r}=7 \mathrm{~Pa}$. These correspond to a specific soil sample containing $50 \%$ kaolinit clay and $50 \%$ of sand that was tested as reported in Pham [13].

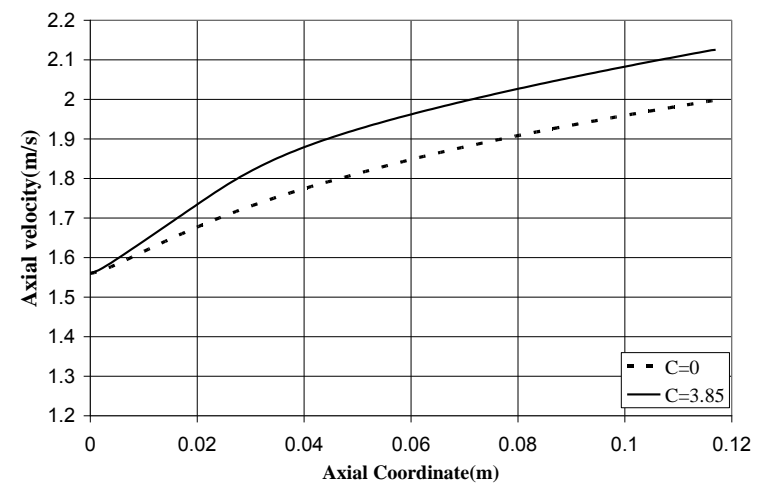

Fig.3. Axial velocity obtained for $\mathrm{P}=3127 \mathrm{~Pa}$ as function of clay concentration

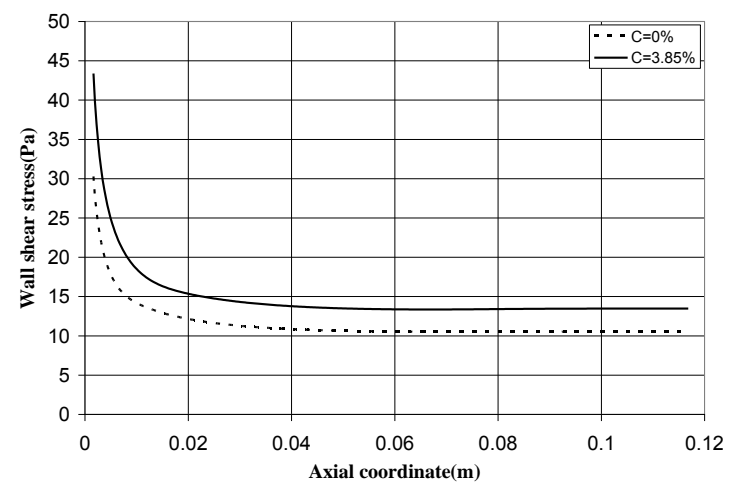

Fig.4. Wall-shear stress obtained for $\mathrm{P}=3127 \mathrm{~Pa}$ as function of clay concentration

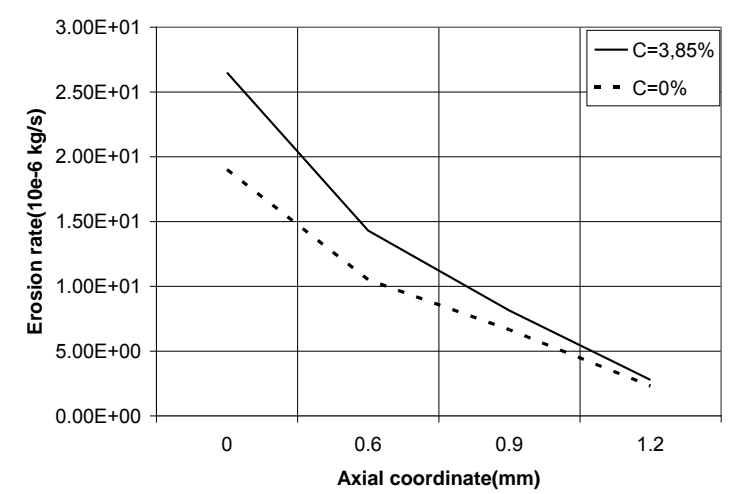

Fig.5. Erosion rate as function of the clay concentration

The obtained results, as shown in figure 5, indicate that erosion rate increase with clay concentration and wit the axial coordinate. This is in contrast with the onedimensional modelling of the HET for which the erosion rate does not depend on the axial coordinate.

\section{Conclusions}

A two-dimensional modelling of the Hole Erosion Test was carried out in this work. Unlike the early models which are essentially one-dimensional, the twodimensional modeling had shown that the wall-shear stress is not uniform along the hole wall of the soil 
sample. It was possible then through using a linear erosion law to predict non uniform erosion along the hole length.

Studying the effect of clay concentration has shown that it has not a negligible effect on the wall-shear stress and thus would affect in its turn surface erosion that develops at the fluid soil sample interface, particularly at the outlet extremity of the hole where it is maximal. This enabled qualitatively understanding why the eroded profile of the hole wall as observed during experiment is not uniform.

\section{Acknowledgement}

The authors would like to thank the Spanish Agency of International Cooperation (AECID) and Moroccan CNRST which have supported financially this research.

\section{References}

1. Foster M.A., Fell R., Spannangle M. The statistics of embankment dam failures and accidents. Canadian geotechnical Journal 37(5), 100-1024, 2000.

2. Fjar E., Holt R.M., Horsrud P., Raaen A.M., Risnes R., Petroleum related rock mechanics, revised edition Elsevier, Amsterdam, 2004.

3. Bonelli S., Brivois O., Borghi R., Benahmed N. On the modelling of piping erosion, Comptes Rendus de Mécanique 89 (334) (2006) 555-559.

4. Lachouette D. Golay F., Bonelli S. One dimensional modelling of piping flow erosion. C. R. Mecanique 336 (2008) 731-736.

5. Bonelli S., Brivois O. The scaling law in the hole erosion test with a constant pressure drop, International Journal of Numerical Methods in Engineering 32 (2008) 1573-1595.

6. Escue A., Cui J. Comparison of turbulence models in simulating swirling pipe flows. Applied Mathematical Modelling. (2010) doi:10.1016/j.apm.2009.12.018.

7. Fieldview reference Manual, Software Release Version 10, Intelligent Light, 2004.

8. Launder B.E., Spalding D.B. Lectures in Mathematical Models of Turbulence. Academic Press, London, England, 1972.

9. Yakhot V., Orszag S.A. Renormalization Group Analysis of Turbulence: I-Basic Theory. Journal of Scientific Computing, 1(1): 1-51, 1986.

10. Choudhury D. Introduction to the Renormalization Group Method and Turbulence Modeling. Fluent Inc. Technical Memorandum TM-107, 1993.

11. Pope S.B. Turbulent flows. Cambridge University Press, 2000.

12. Fluent 6.2 Users Guide. Fluent Inc., 2005.

13. Pham T.L. Erosion et dispersion des sols argileux par un fluide. In French. Ph.D Thesis, Order number: D.U. ED: 430. Ecole Nationale des Ponts et Chaussées, Paris, France, 2008. 